\title{
Potential error in the use of an automated external defibrillator during an in-flight medical emergency
}

\author{
Peter G. Katis, MD; ${ }^{*}$ Solange M. Dias, BSc, EMCA, BScN, RN, MD ${ }^{\dagger}$
}

\begin{abstract}
In-flight medical emergencies are uncommon, generally non-lethal events. In fatal cases, the most common cause of death is a sudden cardiac event. This fact, and the awareness that early defibrillation is the most important determinant of successful cardiac resuscitation, have led to the inacreasing availability of automated external defibrillators (AEDs) aboard commercial airplanes. AEDs are sophisticated and extremely reliable devices that are designed to be used by trained laypersons in the hope of minimizing the crucial time to defibrillation. Although designed to be foolproof, both machine- and operator-dependant usage errors have been recognized. In this case study we report a unique operator-dependent error involving the misreading of an AED instruction window, briefly review the history of AED use in the airline industry, and underscore the need for a sound knowledge of basic life support skills when working with these devices. We conclude by making recommendations to prevent similar errors from occurring in the future.
\end{abstract}

Key words: in-flight medical emergency; airplane; AED; automated external defibrillator; error

\begin{abstract}
RÉSUMÉ
Les urgences médicales pendant un vol sont des événements peu courants et généralement non fatals. Dans les cas fatals, la cause la plus courante de mortalité est l'arrêt cardiaque subit. Cet état de chose et la notion selon laquelle la défibrillation précoce est le facteur déterminant le plus important d'une réanimation cardiaque réussie ont mené à une disponibilité accrue des défibrillateurs externes automatisés (DEA) à bord des vols commerciaux. Les DEA sont des appareils perfectionnée et extrêmement fiables conçus pour être utilisés par des profanes formés à leur utilisation dans l'espoir de minimiser le délai crucial jusqu'à la défibrillation. Bien que les appareils soient conçus pour être infaillibles, des erreurs d'utilisation liées aux appareils eux-mêmes ainsi qu'à des opérateurs ont été relevées. Dans le cas à l'étude, nous présentons une erreur unique imputable à un opérateur impliquant la lecture erronée d'une fenêtre d'instruction d'un DEA. Nous passons brièvement en revue l'historique du recours aux DEA par l'industrie de l'aviation et nous insistons sur le besoin d'une bonne connaissance des soins de base en réanimation lors de l'utilisation de ces appareils. Nous concluons en faisant des recommandations pour éviter que des erreurs semblables ne se répètent dans le futur.
\end{abstract}

\footnotetext{
*Assistant Medical Director, Emergency Medicine, University Health Network, Toronto, Ont.; Lecturer, Department of Family and Community Medicine, University of Toronto, Toronto, Ont.

†Postgraduate Year 1, Department of Family Medicine, University of Toronto, Toronto, Ont.
}

Received: Sept. 23, 2003; final submission: Nov. 8, 2003; accepted: Nov. 11, 2003

This article has been peer reviewed.

Can J Emerg Med 2004;6(1):45-7 


\section{Introduction}

In-flight medical emergencies are relatively rare. ${ }^{1}$ The incidence of these events has been estimated to be between 1 per $10000-40000$ passengers or 1 per 753 flights. ${ }^{1-6} \mathrm{Fa}-$ talities are rarer still, with an estimated incidence of $0.3-1$ per 1000000 passengers. ${ }^{2,6}$ Despite this, the high volume of airline passengers (more than 1 billion annually, worldwide) results in an estimated 25000 to 30000 calls for medical help each year. ${ }^{4}$ Cardiac-related complications are one of the most common types of complaints reported. ${ }^{2,3,7}$ Moreover, when an in-flight fatality does occur, the most common cause of death is a sudden cardiac event. ${ }^{2}$

\section{Case report}

During a transatlantic flight the cabin crew requested medical assistance for a 65-year-old woman who had been complaining of chest pain and shortness of breath, and who had subsequently become unresponsive. Two physicians (P.G.K. and S.M.D.) responded.

The patient had a history of hypertension, for which she took a beta-blocker, but had no previous history of cardiac or respiratory disease. However, past medical history was significant for anxiety attacks, for which she took clonazepam on an as-needed basis. After the onset of her symptoms, she had taken two 2.5 -mg tablets of clonazepam, but without relief.

She was placed on the floor by the flight attendants, and then the call for help was made. Witnesses reported that prior to becoming unresponsive she had appeared anxious, diaphoretic and was hyperventilating.

The physicians requested the airplane's automated external defibrillator (AED), and a set of vitals was performed, yielding a heart rate of 55 beats/min., a blood pressure of $90 / 60 \mathrm{~mm} \mathrm{Hg}$, and a respiratory rate of 12 breaths/min. Following AED attachment, one of the flight attendants read the message, "Start CPR," from the AED screen and prepared to begin chest compressions. After confirming spontaneous respirations and a palpable pulse, the physicians advised the attendant not to start CPR. A second look at the display screen revealed alternate toggling of the message "Start CPR" with the message ". . if no pulse."

\section{Discussion}

Early access to defibrillation is the major determining factor of successful resuscitation in an individual with a malignant dysrhythmia. ${ }^{8}$ Consequently, there has been a shift in recent years toward greater public access to AEDs for out- of-hospital cardiac arrests, especially in crowded venues, where the likelihood of encountering a cardiac arrest is greatest. ${ }^{9}$ Targeted locations for public access defibrillation programs include, but are not limited to, sporting events, shopping malls, office towers, casinos, airports and airplanes. ${ }^{8}$ These programs place AEDs in the hands of trained laypersons in order to maximize the number of potential responders and minimize the crucial time to defibrillation. ${ }^{8}$

AEDs are sophisticated and reliable computerized devices that are intended to be simple to operate. ${ }^{8}$ There are two types of AED: 1) semi-automatic defibrillators, which analyse cardiac rhythm and, if indicated, advise the operator to defibrillate - usually by pressing a button; and 2) automatic defibrillators, which defibrillate in a fully automatic fashion. ${ }^{8}$ Clinical studies have confirmed the safety of AEDs in out-of-hospital settings and documented high sensitivity and specificity with respect to arrhythmia analysis. ${ }^{8,10,11}$

Despite the "foolproof" nature of these devices, errors in use have been reported. ${ }^{12,13}$ Typically these errors involve undelivered electrical shocks, and there is an approximately equal proportion of machine-related and operatorrelated errors. ${ }^{12}$ Operator-dependent errors include the following: ${ }^{12}$

- patient movement that interferes with analysis;

- prematurely turning off the AED;

- failing to deliver an electrical shock as instructed; and

- failure to recognize the loosening of monitor leads during analysis.

This case report illustrates a different type of error:

- the inappropriate intention to start cardiopulmonary resuscitation (CPR) in a patient with a pulse and spontaneous respiration.

This is the first case report of operator-related error involving the misreading of an AED instruction window, which would have led to unnecessary CPR. We believe a contributing factor in this case was the splitting of the message, "Start CPR ... if no pulse." In this stressful context, the second component of the message was overlooked, and the AED instructions were misinterpreted as merely, "Start CPR." The potential for error was heightened by the presence of an inexperienced operator lacking familiarity with basic life-support skills.

Airline industry personnel provide medical assistance in $51 \%$ of in-flight emergencies but, interestingly, there are no international standards dealing with flight crew medical training or in-flight medical equipment availability. ${ }^{2,3}$ How- 
ever, in April 2001 the US Federal Aviation Administration issued a rule requiring all commercial aircraft with at least one flight attendant to carry AEDs by $2004 .{ }^{14}$ In commercial air transport, the carriage of AEDs has been addressed by some civil aviation authorities, but not by the International Civil Aviation Organization (ICAO) and its standards and recommended practices. The ICAO is not aware of any international standards (ICAO: personal communication, 2003 Nov 21). Moreover, commercial airlines are under no legal obligation to provide medical care. ${ }^{2}$ This is in contrast to the early years of commercial air travel, when nurses served as flight attendants. ${ }^{2}$ Presently, a large proportion of flight attendants are not even certified to provide basic life support, yet despite this, AED availability has increased within the airline industry since 1996 when the US Food and Drug Administration (FDA) approved their use on commercial aircraft. ${ }^{14}$ Transport Canada now encourages AED use, and many European carriers have included them as standard medical equipment for a number of years. ${ }^{15}$

When an in-flight medical emergency occurs, crew members often ask passengers with medical training for assistance. ${ }^{7}$ It is therefore imperative that physicians who respond to these situations be familiar with AEDs and have a sound knowledge of basic life-support skills. Medical personnel should recognize that AED devices were intended for layperson use, do not display the rhythm being analysed, cannot be relied upon to diagnose underlying rhythm disturbances, and that there is the potential for error. ${ }^{14}$ AEDs should be viewed as an adjunct to basic life support and a key component of the "chain of survival," which includes early access, early CPR and early defibrillation. ${ }^{8}$

Manufacturers of AEDs should increase the display screen character capacity to avoid dividing critical instructions between multiple screens. Alternatively, a universal adoption of AED models with voice prompts (which the device in this situation lacked) may be preferable. These modifications would reduce the potential for the type of error almost committed in this case.

Despite repeated requests to the airline for confirmation of the manufacturer and model number of the AED involved, we have not received a response.

\section{Conclusion}

The patient regained consciousness after a brief period in the supine position. Her vital signs remained stable, and her chest pain resolved. The remainder of the flight was uneventful, and when the plane landed she was escorted to a nearby hospital for further evaluation.

Competing interests: None declared.

\section{References}

1. Wallace TW, Wong T, O'Bichere A, Ellis BW. Managing inflight emergencies. BMJ 1995;311(7001):374-6.

2. Jagoda A, Pietrzak M. Medical emergencies in commercial air travel [review]. Emerg Med Clin North Am 1997;15(1):159-64.

3. Cummins RO, Schubach JA. Frequency and types of medical emergencies among commercial air travelers. JAMA 1989;261(9):1295-9.

4. Kay RS. Safe air travel. Preventing in-flight medical problems. Nurse Pract 1994;19(5):39,43-6.

5. Speizer C, Rennie CJ 3rd, Breton H. Prevalence of in-flight medical emergencies on commercial airlines. Ann Emerg Med 1989;18(1):26-9.

6. Rosenberg CA, Pak F. Emergencies in the air: problems, management, and prevention [review]. J Emerg Med 1997;15(2):159-64.

7. Hunter A. Will you volunteer in-flight medical care? CMAJ 1980;123(2):137-40.

8. Guidelines 2000 for cardiopulmonary resuscitation and emergency cardiovascular care. Part 4: the automated external defibrillator: key link in the chain of survival. The American Heart Association in collaboration with the International Liaison Committee on Resuscitation. Circulation 2000;102(8 suppl):I60-76.

9. Mears GD, Yancey AH. Mass gatherings. In: Tintinalli J, Kelen G, Stapczynski J, editors. Emergency medicine: a comprehensive study guide. 5th ed. New York: McGraw-Hill; 2000. p. 32-6.

10. Stults KR, Brown DD, Kerber RE. Efficacy of an automated external defibrillator in the management of out-of-hospital cardiac arrest: validation of the diagnostic algorithm and initial clinical experience in a rural environment. Circulation 1986;73:701-9.

11. Dickey W, Dalzell GW, Anderson JM, Adgey AA. The accuracy of decision-making of a semi-automatic defibrillator during cardiac arrest. Eur Heart J 1992;13:608-15.

12. MacDonald RD, Swanson JM, Mottley JL, Weinstein C. Performance and error analysis of automated external defibrillator use in the out-of-hospital setting. Ann Emerg Med 2001;38(3):262-7.

13. Cummins RO, White RD, Pepe PE. Ventricular fibrillation, automatic external defibrillators, and the United States Food and Drug Administration: confrontation without comprehension. Ann Emerg Med 1995;26(5):621-31.

14. Federal Aviation Administration. Emergency medical equipment, 66 Federal Register. 19028 (2001).

15. Drummond R, Drummond AJ. On a wing and a prayer: medical emergencies on board commercial aircraft. Can J Emerg Med $2002 ; 4(4): 276-80$.

Correspondence to: Dr. P.G. Katis, Toronto General Hospital, R. Fraser Elliot Building, GS-434, 200 Elizabeth St., Toronto ON M5G 2C4; 416 340-3856, fax 416 340-4300, peter.katis@uhn.on.ca 